\title{
CCK1-Receptor Stimulation Protects Against Gut Mediator-Induced Lung Damage During Endotoxemia
}

\author{
Friederike Eisner ${ }^{\mathrm{a}, \mathrm{b}} \quad$ Elizabeth M. Martin ${ }^{\mathrm{b}} \quad$ Markus A. Küper ${ }^{\mathrm{a}} \quad$ Helen E. Raybould $^{\mathrm{b}}$ \\ Jörg Glatzlea
}

aDepartment of General, Visceral and Transplant Surgery, University Hospital of Tuebingen, Tuebingen, Germany; ${ }^{b}$ Department of Anatomy, Physiology and Cell Biology, School of Veterinary Medicine, University of California Davis, Davis, CA, USA

\section{Key Words}

Sepsis • Endotoxemia $\cdot$ Innate immunity $\cdot$ Mucosal immunity $\bullet$ Cholinergic anti-inflammatory pathway $\cdot$ Cholecystokinin

\begin{abstract}
Background/Aims: Cholecystokinin 1-receptor (CCK1-R) activation by long chain fatty acid (LCFA) absorption stimulates vago-vagal reflex pathways in the brain stem. The present study determines whether this reflex also activates the cholinergic anti-inflammatory pathway, a pathway known to modulate cytokine release during endotoxemia. Methods:Mesenteric lymph was obtained from wild type (WT) and CCK1-R knockout (CCK1- $\mathrm{R}^{-/}$) mice intraperitoneally challenged with Lipopolysaccharid (LPS) (endotoxemic lymph, EL) and intestinally infused with vehicle or LCFA-enriched solution. The lymph was analyzed for TNF $\alpha$, IL- 6 and IL-10 concentration and administered to healthy recipient mice via jugular infusion. Alveolar wall thickness, myeloperoxidase (MPO) and TUNEL positive cells were determined in lung tissue of recipient mice. Results: LCFA infusion in WT mice reduced TNF $\alpha$ concentration in EL by $49 \%$ compared to vehicle infusion, but had no effect in CCK1-R ${ }^{-1-}$ mice. EL significantly increased the alveolar wall thickness, the number of MPO-positive and TUNEL-positive cells compared to control lymph administration. LCFA infusion in WT, but not in CCK1R ${ }^{--}$mice, significantly reduced these pathological effects of EL. Conclusion: During endotoxemia enteral LCFA absorption reduces TNF $\alpha$ release into mesenteric lymph and attenuates histomorphologic parameters of lung dysfunction. Failure to elicit this effect in CCK1 $1 \mathrm{R}^{--}$mice demonstrates that anti-inflammatory properties of LCFAs are mediated through CCK1-Rs.
\end{abstract}

Copyright $\odot 2013$ S. Karger AG, Basel

Jörg Glatzle
Department of General-, Visceral- and Transplant Surgery, University of Tübingen Hoppe-Seyler-Strasse 3, D-72076 Tübingen (Germany)

Tel. +49-7071-2985073, E-Mail Joerg.Glatzle@med.uni-tuebingen.de 


\section{Introduction}

In spite of all advances in antimicrobial therapy and intensive care treatment, severe sepsis and septic shock remain a major challenge on intensive care units and are a common cause of death in industrialized countries $[1,2]$.

Sepsis is a heterogeneous and dynamic disease characterized by the systemic manifestation of inflammation induced by a microorganism $[3,4]$. The crucial step for the rapid initiation of host defense responses after microbial infection is generally considered to be the activation of pattern-recognition receptors (PRR) such as toll-like receptors (TLR) [5-7]. During sepsis, the release of high levels of pathogen-associated molecular patterns (PAMP) and/or intracellular proteins and molecules from dying cells (so called alarmins [5]) induce an overwhelming activation of mediators, free radicals and enzymes. Thereby, the normally protective inflammatory response grows to a severe life-threatening inflammatory state [8]. With loss of regulatory function, the local response can lead to organ dysfunction at sites far from the initial site of infection. This condition, referred to as severe sepsis [4], most frequently effects the respiratory system, followed by cardiovascular dysfunction, coagulation disorders, renal failure, CNS derangements, and hepatic dysfunction [1]. A progressive dysfunction in two or more organ systems is referred to as multiple organ dysfunction syndrome (MODS) [3, 9].

Signs of a systemic inflammation, similar to those observed during sepsis, can develop in the absence of an invasive infection e.g. in pancreatitis or severe trauma. This finding led to the concept of a systemic inflammatory response syndrome (SIRS) [3, 4]. Likewise the toxic effect of Lipopolysaccharide (LPS) is due to a powerful immune response triggered by the LPS - leukocyte interaction eventually resulting in shock and MODS [7, 10]. LPS, also referred to as endotoxin, is an important component of the outer membrane of Gram-negative bacteria [10]. LPS signaling is mediated by TLR4, a member of the TLR family expressed on the surface of antigen-presenting cells such as macrophages, dendritic cells and B cells [7, $11,12]$. Ligand binding to TLR4 results in synthesis and release of inflammatory cytokines $[7,13]$. It has been demonstrated, that the pro-inflammatory cytokines Interleukin (IL)1 and tumor necrosis factor (TNF) $\alpha$ can elicit pathological responses similar to clinical features of sepsis [14]. All together these observations support the concept of host-derived non-bacterial factors as major cause of the MODS $[4,15]$.

The gut associated lymphoid tissue (GALT) is the largest lymphoid organ [16]. The associated immune cells are unique in their properties which enable both tolerance to huge amounts of microbes and antigens as well as protection against harmful pathogens $[16,17]$. Disruption of the intestinal integrity by infection, ischemia or trauma expeditiously results in SIRS or sepsis eventually leading to MODS $[15,18]$. A pivotal role of mesenteric lymph in dispersing pro-inflammatory factors during experimental endotoxemia $[19,20]$, trauma and hemorrhagic shock [21-23] has been shown recently. Immune cells and pro-inflammatory mediators are released from the gut wall into mesenteric lymph and drained into the systemic circulation via the thoracic duct. Thus, the pulmonary vascular bed is the first vascular bed exposed to mediators carried by mesenteric lymph [18]. Severe sepsis, major trauma with hemorrhage and shock as well as severe pancreatitis are frequent causes of acute lung injury (ALI) and the acute respiratory distress syndrome (ARDS) [1, 24]. An incidence of about 200,000 people annually with approximately $40 \%$ fatal outcome is reported in the United States [24]. In experimental models of trauma, hemorrhagic shock and burns lung injury could be reduced or even prevented by mesenteric lymph duct division [25-28] accounting for mesenteric lymph as primary route for gut-derived inflammatory factors.

Recent studies have revealed the prominent role of autonomic control of the immune system in inflammatory disease. Information about locally released inflammatory mediators is transmitted to the central nervous system (CNS) via afferent nerves and the bloodstream. As a result, the CNS modulates immune responses through complex integration of neural, cytokine, and hormonal inputs, resulting in efferent vagal function forming the so called cholinergic anti-inflammatory pathway $[29,30]$. The idea of a cholinergic anti-inflammatory 
pathway was first formulated by Tracey and colleagues, who determined that electrical stimulation of the cervical vagal nerve before and after intravenous LPS administration diminished both TNF $\alpha$ levels in serum and liver and the development of septic shock [29]. In vitro culture of isolated human macrophages demonstrated that acetylcholine reduced the release of pro-inflammatory cytokines TNF $\alpha$, IL-6, IL-1 $\beta$, IL-18 but had no effect on antiinflammatory IL-10 levels [29]. They identified the nicotinic acetylcholine receptor alpha 7 (n $\alpha 7 \mathrm{AChR}$ ) to be present in macrophages and responsible for the anti-inflammatory effect observed [31].

There is evidence for the ability of macronutrients to modulate the systemic inflammatory response via the autonomic nervous system. The interaction of nutrition and the nervous system is known to be crucial for the regulation of gut motility and digestion as well as food intake and satiety. Investigation into the role of nutrient modulation of the cholinergic anti-inflammatory pathway has shown that ingestion of lipids attenuated TNF $\alpha$ serum levels in rodent models of hemorrhagic shock [32] and endotoxemia [33]. Previously, we demonstrated that ingestion of long chain fatty acids (LCFA) decreased TNF $\alpha$ levels in the mesenteric lymph and reduced the damaging effect of endotoxemic mesenteric lymph to the lung tissue in a rat model [19]. The observation, that vagotomy as well as a combined antagonism of cholecystokinin 1- and cholecystokinin 2- receptors (CCK1-R and CCK2-R) counteract the protective lipid effect $[32,33]$ provided first hints about the involvement of the vagal afferent pathway. Fatty acids with a chain length of ten or more carbon atoms trigger the release of the peptide hormone cholecystokinin (CCK) from specialized enteroendocrine cells in the proximal small intestine. Vagal afferent nerve terminals, expressing predominantly CCK1-R, are located in immediate adjacency to CCK-producing cells and are activated by CCK [34].

At present, there is lack of evidence for the critical role of CCK1-Rs in mediating the anti-inflammatory impact of enteral lipid absorption. It also remains unclear whether the release of cytokines, in addition to TNF $\alpha$, into mesenteric lymph is influenced by absorption of LCFA. The present study uses a CCK1-R knockout mouse model of endotoxemia to address these questions.

\section{Material and Methods}

\section{Animals}

Experiments were performed using male 129S6/SvEv mice (hereafter referred to as WT, Taconic Farms, Oxnard, CA and CCK1-Receptor knockout mice (hereafter referred to as CCK1-R $/$ mice, 129S6/SvEv background) of 20-30g weight. CCK1-R $\mathrm{R}^{-/}$mice display normal body weight and are normoglycemic [35]. Animals were maintained on commercially available laboratory chow (Purina Laboratory, diet \#5001, St. Louis, MO) and were housed under controlled conditions of illumination (12:12 h light/ dark cycle starting at 6 p.m.), humidity, and temperature $\left(21^{\circ} \mathrm{C}\right)$ with free access to food and water. Before surgical procedures, animals were fasted for 18 hours but allowed water and a $5 \%$ glucose solution ad libitum. Institutional guidelines for the care and use of laboratory animals were followed throughout the study.

\section{Mesenteric lymph collection}

The method of mesenteric lymph duct cannulation was previously published [36]. In brief, animals were anesthetized using a combination of Isoflurane (Piramal Healthcare, India) and i.p. Methohexital Sodium (50mg/kg BW, JHP Pharmaceuticals, USA). A laparotomy was performed through a midline incision, the superior mesenteric lymph duct was identified using a microscope, and a polyurethane tube was inserted into the lymph duct (Micro-Renathane, $0.64 \mathrm{~mm}$ O.D. x 0.30mm I.D., Braintree Scientific, Inc., USA). The tube was fixed in place with a drop of cyanoacryl glue (Krazy Glue, Elmer's Products Inc., USA) and externalized through an incision in the right flank. A second catheter (Silastic, 1.65mm O.D. x 0.76mm I.D., Dow Corning Corporation, USA) was placed into the duodenum through the fundus of the stomach, fixed with a polypropylene suture, and externalized through the left flank. Buprenorphine $0.05 \mathrm{mg} / \mathrm{kg}$ BW, s.c., Reckitt Benckiser Pharmaceuticals Inc., USA) was administered postoperatively. To prevent catheters from dislocation, mice were placed in modified Bollman cages after surgery. A glucose-electrolyte solution 
(Glucose $0.2 \mathrm{~mol} / \mathrm{L}, \mathrm{NaCl} 145 \mathrm{mmol} / \mathrm{L}$, and $\mathrm{KCl} 4 \mathrm{mmol} / \mathrm{L}$ with or without $1 \%$ ClinOleic, a mixture of $80 \%$ olive oil and 20\% soybean oil, Baxter, Germany) was infused continuously through the duodenal cannula at a rate of $0.5 \mathrm{ml} / \mathrm{h}$. Mice were allowed to recover from surgery for 12 hours while the mesenteric lymph was drained freely and mice were intestinally infused as above mentioned. Thereafter, mesenteric lymph was collected for two hours before (control lymph) and for a six hours after i.p. LPS injection (LPS, Escherichia coli serotype 0111:B4, Sigma, USA, $5 \mathrm{mg} / \mathrm{kg}$ body weight in $0.2 \mathrm{ml}$, endotoxemic lymph) from four different experimental groups ( $\mathrm{n}=8$ per group):

(I) WT mice, intestinally infused with vehicle solution (Glucose $0.2 \mathrm{~mol} / \mathrm{L}, \mathrm{NaCl} 145 \mathrm{mmol} / \mathrm{L}$, and $\mathrm{KCl}$ $4 \mathrm{mmol} / \mathrm{L})$.

(II) WT mice, intestinally infused with long chain fatty acid (LCFA) solution (1\% ClinOleic, Glucose $0.2 \mathrm{~mol} / \mathrm{L}, \mathrm{NaCl} 145 \mathrm{mmol} / \mathrm{L}$, and $\mathrm{KCl} 4 \mathrm{mmol} / \mathrm{L}$ ).

(III) CCK1-R $\%$ mice, intestinally infused with vehicle solution (Glucose $0.2 \mathrm{~mol} / \mathrm{L}, \mathrm{NaCl} 145 \mathrm{mmol} / \mathrm{L}$, and $\mathrm{KCl} 4 \mathrm{mmol} / \mathrm{L})$.

(IV) CCK1-R $\mathrm{R}^{\%}$ mice, intestinally infused with LCFA solution (1\% ClinOleic, Glucose 0.2mol/L, NaCl 145 $\mathrm{mmol} / \mathrm{L}$, and $\mathrm{KCl} 4 \mathrm{mmol} / \mathrm{L})$.

Lymph was collected in two hour time intervals in ice-chilled tubes, centrifuged at $2000 \mathrm{~g}$, frozen and stored at $-80^{\circ} \mathrm{C}$ for further experiments.

\section{Lymph cytokine determination}

Concentration of TNF $\alpha$, IL- 6 and IL-10 was determined by multiplex bead-based assays (Bio-Plex, Bio-Rad, USA) according to the manufacturer's protocol. Briefly, $50 \mu$ l aliquots of diluted lymph samples and cytokine standards were incubated in a 96-well filter plate with capture antibody-coupled beads for $30 \mathrm{~min}$ at room temperature while protected from light and with modest shaking. After three washing steps detection antibodies were added and incubated for 30min. Samples were washed and 10min incubated with Streptavidin-PE. Thereafter samples were washed and re-suspended in Assay Buffer (Bio-Rad, USA). The Bio-Plex System (Luminex xMAP-Technology, Bio-Rad, USA) was used for data acquisition and cytokine concentration were calculated using the Bio-Plex Manager software, version 4.0 (Bio-Rad, USA).

\section{Mesenteric lymph infusion}

Mesenteric lymph samples of eight donor mice from each of the groups I-IV were pooled for the collection period before LPS administration (control lymph) and after LPS administration (endotoxemic lymph). The lymph was then infused $(0.25 \mathrm{ml} / \mathrm{h}, 90 \mathrm{~min})$ in separate healthy recipient WT mice through a catheter in the jugular vein (Micro-Renathane, 0.64mm O.D. x 0.30mm I.D., Braintree Scientific, Inc., USA).

Mesenteric lymph infusion was performed in 6 different experimental groups:

(A) WT mice control lymph (CL): Infusion of lymph obtained from WT mice intestinally infused with vehicle solution $(n=4)$.

(B) WT mice Endotoxemic lymph (EL): Infusion of lymph obtained from WT mice intestinally infused with vehicle solution $(n=6)$.

(C) WT mice EL LCFA: Infusion of lymph obtained from WT mice intestinally infused with LCFA solution and LPS administration $(n=5)$.

(D) CCK1-R $\mathrm{R}^{-/}$mice CL: Infusion of lymph obtained from CCK1- $\mathrm{R}^{-/}$mice intestinally infused with vehicle solution $(n=4)$.

(E) CCK1-R $\mathrm{R}^{-/}$mice EL: Infusion of lymph obtained from CCK1-R $\mathrm{R}^{-/}$mice intestinally infused with vehicle solution and LPS administration $(n=6)$.

(F) CCK1-R $\mathrm{R}^{-/}$mice EL LCFA: Infusion of lymph obtained from CCK1- $\mathrm{R}^{-/-}$mice intestinally infused with LCFA solution and LPS administration $(\mathrm{n}=6)$.

\section{Histological Analysis of Lung Tissue}

The lung of the recipient mice was harvested immediately after the termination of lymph infusion and fixed in 4\% PBS- paraformaldehyde. The fixed lung tissue was then embedded in paraffin. Paraffin sections $(1 \mu \mathrm{m})$ were deparaffinized stepwise and incubated with Hematoxylin and Eosin (H\&E), Myeloperoxidase (MPO), or the In-Situ-Cell-Death-Detection Kit (POD, Roche, Penzberg, Germany).

To determine the thickness of the alveolar walls the histological sections were stained with H\&E. The diameter of 30 alveolar walls was determined in one optical section (W: 650pp, F: 515pp) using the Quantimet System (Leica, magnification x 400). Ten optical sections were analyzed for each animal. 
A)

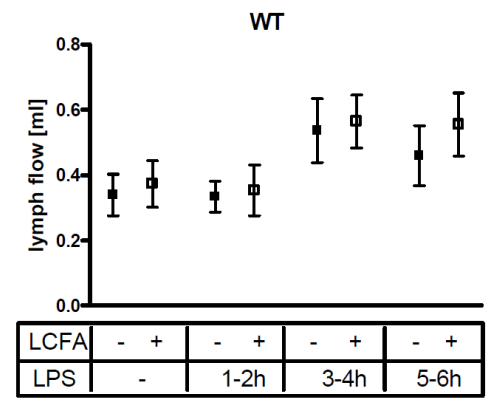

B)

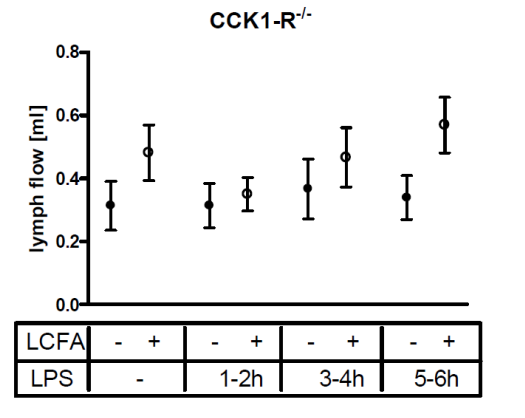

Fig. 1. Mesenteric lymph flow $(\mathrm{ml})$ was determined in two hour $(\mathrm{h})$ time intervals before and after i.p. LPS administration ( $5 \mathrm{mg} / \mathrm{kg}$ body weight) in A) wild type (WT) mice and B) CCK1-receptor knockout (CCK1-R ${ }^{-/}$) mice. Mesenteric lymph flow was affected by neither LPS administration nor intestinal long chain fatty acid absorption.

For MPO immunohistochemistry and the TUNEL reaction histological sections were pre-incubated with 30\% hydrogen peroxide in methanol for 15 minutes in order to block the endogenous peroxidase. By incubation in $20 \%$ swine serum for 20 minutes nonspecific background staining was blocked. The tissue was then incubated overnight with a rabbit anti-MPO antibody (1:50, Dianova, Germany) at room temperature. Thereafter specimens were washed in phosphate-buffered saline and for 60 minutes incubated with a biotinylated, swine anti-rabbit antibody (1:600, DAKO, Germany) at room temperature. The avidinbiotin complex $(\mathrm{ABC})$ method was used to demonstrate MPO immunoreactivity with 3,3'diaminobenzidine $0.05 \%$ /hydrogen peroxide $0.033 \%$ (DAB) serving as chromagen. For each animal MPO positive cells were determined in 30 optical sections.

The In-Situ-Cell-Death-Detection Kit (Roche, Germany) was used for detection of apoptotic cells following the manufacturer's instruction. In short, after blocking of the endogenous peroxidase histological sections were five minutes pretreated with microwave irradiation (700 Watt) in $0.01 \mathrm{M}$ citrate buffer (pH 6.0). Background was diminished by preincubating with $3 \%$ bovine serum albumin (BSA) in $0.1 \mathrm{M}$ Tris- $\mathrm{HCl}$. Afterwards the specimens were incubated for one hour at $37^{\circ} \mathrm{C}$ with the TUNEL labeling mix. POD was used for signal conversion and TUNEL positive cells were demonstrated by the DAB color reaction. For each animal TUNEL positive cells were determined in 30 optical sections.

For the statistical calculation the average value of the thickness of the alveolar walls, number of MPOpositive cells and TUNEL-positive cells of all optical sections of one specimen were used as a single value.

Statistical analyses

Data are presented as mean \pm standard error of the mean (SEM). Differences between the groups were determined by unpaired Student's t-test using the software package of GraphPad Prism 4.0 (San Diego, CA). A probability of $\mathrm{p}<0.05$ was taken as significant.

\section{Results}

Mesenteric lymph flow

The amount of mesenteric lymph collected in the two hour time intervals was between $0.3 \mathrm{ml}$ and $0.6 \mathrm{ml}$. There was no significant effect of treatment with LPS or intestinal LCFA on lymph flow (Fig. 1).

LPS challenge provoked a cytokine release into mesenteric lymph which differed between WT and CCK1-R $R^{-}$mice

Before LPS administration, the concentration of pro-inflammatory TNF $\alpha$ and antiinflammatory IL-10 in mesenteric lymph was similar in WT and CCK1-R ${ }^{-1}$ mice (TNF $\alpha$ : 19 $\pm 5 \mathrm{pg} / \mathrm{ml}$ vs. $11 \pm 4 \mathrm{pg} / \mathrm{ml}$; IL-10: $37 \pm 12 \mathrm{pg} / \mathrm{ml}$ vs. $38 \pm 11 \mathrm{pg} / \mathrm{ml}$, WT and CCK1-R $/-$ mice respectively; not significant). In contrast, the concentration of pro-inflammatory IL- 6 was 
Fig. 2. Cytokine concentration in mesenteric lymph was determined before and after LPS challenge in both genotypes intestinally infused with either vehicle or long chain fatty acid solution. LPS challenge provoked a cytokine release into mesenteric lymph which differed between WT and CCK1$\mathrm{R}^{\circ /-}$ mice. Intestinal long chain fatty acid (LCFA) absorption decreased $\mathrm{TNF} \alpha$ release into mesenteric lymph in WT mice but not in CCK1$\mathrm{R}^{-/-}$mice. IL-6 and IL10 concentration were not affected by LCFA absorption. Mesenteric lymph concentration of A) TNF $\alpha$ in wild type (WT) mice; B) $\mathrm{TNF} \alpha$ in CCK1-R knockout $\left(\mathrm{CCK} 1-\mathrm{R}^{-\%}\right)$ mice; C) IL-6 in WT mice; D) IL-6 in CCK1-R ${ }^{-/}$mice; E) IL-10 in WT mice and F) IL-10 in CCK1$\mathrm{R}^{-1-}$ mice before and up to six hours (h) after i.p. LPS administration (5mg/kg body weight) was determined via multi-bead ELISA. * $\mathrm{p}<0.05$ vehicle infusion
A)

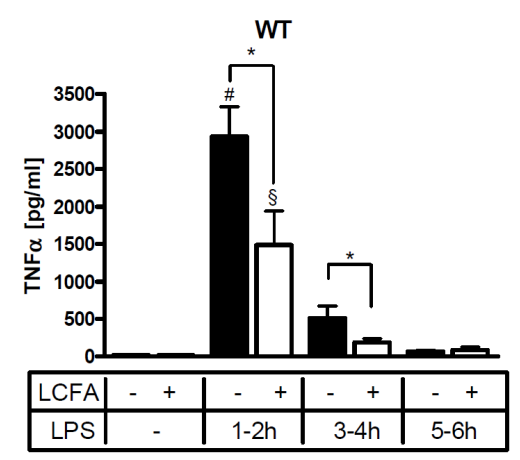

C)

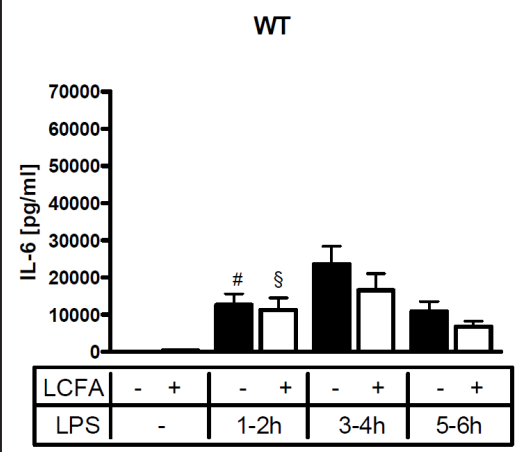

E)

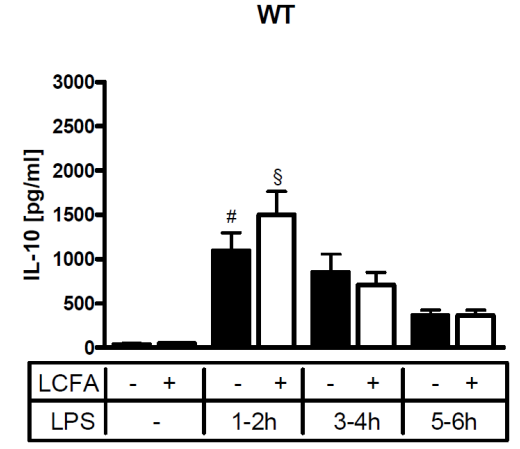

B)

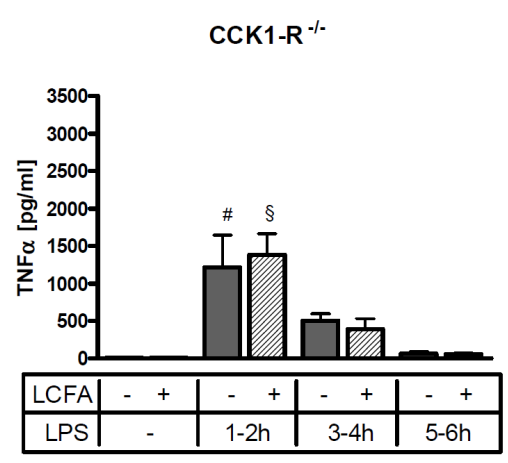

D)

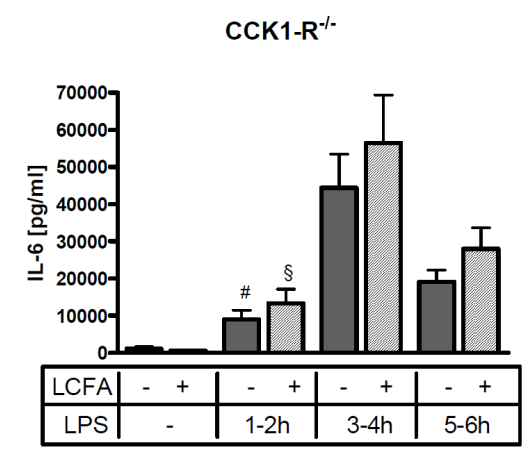

F)

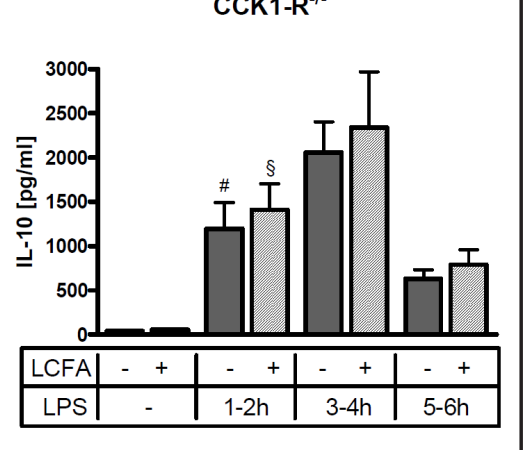

vs. LCFA infusion, * $\mathrm{p}<0.05$ control lymph vs. endotoxemic lymph collected during vehicle infusion, ${ }^{\S} \mathrm{p}<0.05$ control lymph vs. endotoxemic lymph collected during LCFA infusion.

lower in WT mice $(96 \pm 37 \mathrm{pg} / \mathrm{ml})$ compared to CCK1 $-\mathrm{R}^{-/}$mice $(1166 \pm 473 \mathrm{pg} / \mathrm{ml})(\mathrm{p}<0.05)$ (Fig. 2).

In both genotypes, LPS treatment increased the release of TNF $\alpha$, IL- 6 and IL-10 into the mesenteric lymph. However, time to peak concentrations, as well as maximal concentration reached differed between the cytokines.

Maximal TNF $\alpha$ levels were reached in the first two hours after LPS challenge. TNF $\alpha$ concentrations increased 154 fold in WT mice $(\mathrm{p}<0.05)$ and 113 fold in CCK1-R $\mathrm{R}^{-/}$mice from baseline $(\mathrm{p}<0.05)$ in the first two hours after LPS application. TNF $\alpha$ rapidly dropped down three to four hours after LPS administration in both genotypes.

IL-6 concentration in the mesenteric lymph peaked three to four hours and decreased moderately to a still marked elevation five to six hours post LPS challenge. WT mice exhibited 
Fig. 3. Histomorphologic parameters of lung dysfunction were determined after jugular infusion of mesenteric lymph in lung tissue of recipient wild type mice. Jugular infusion of endotoxemic lymph provoked an inflammatory reaction in the lung of recipient mice. Long chain fatty acid (LCFA) absorption during endotoxemia in WT donor mice attenuated the lung damage. In contrast LCFA absorption during endotoxemia in donor mice lacking CCK1-R did not prevent inflammatory lung damage. A) thickness of the alveolar walls, B) number of MPO positive cells and C) number of TUNEL positive cells in lung tissue of wild type (WT) mice after jugular infusion of mesenteric lymph. Lymph was harvested from (I) WT mice intestinally infused with vehicle solution, (II) WT mice intestinally infused with vehicle solution during endotoxemia, (III) WT mice intestinally infused with LCFA solution during endotoxemia, (IV) CCK1-R knockout (CCK1-R ${ }^{-/}$) mice intestinally infused with vehicle solution, (V) CCK1- $\mathrm{R}^{-/}$mice intestinally infused with vehicle solution during endotoxemia, and (VI) CCK1- $\mathrm{R}^{-/}$mice intestinally infused with LCFA solution during endotoxemia. ${ }^{*} \mathrm{p}<0.05$ control lymph vs. endotoxemic lymph, ${ }^{*}$ p $<0.05$ vehicle infusion vs. LCFA infusion.

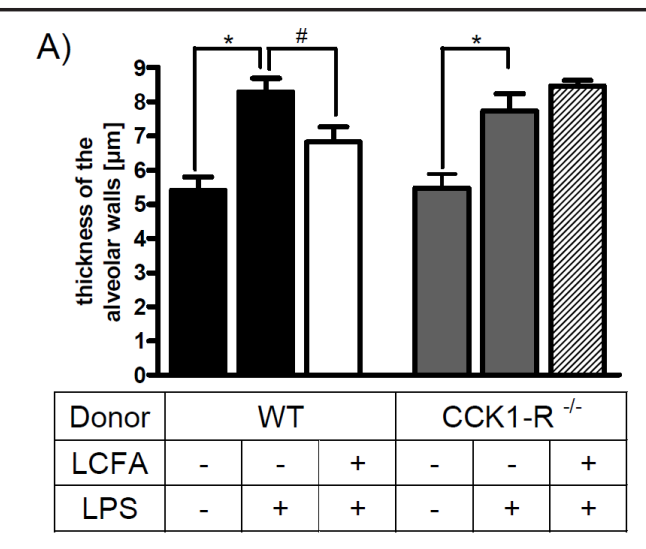

B)

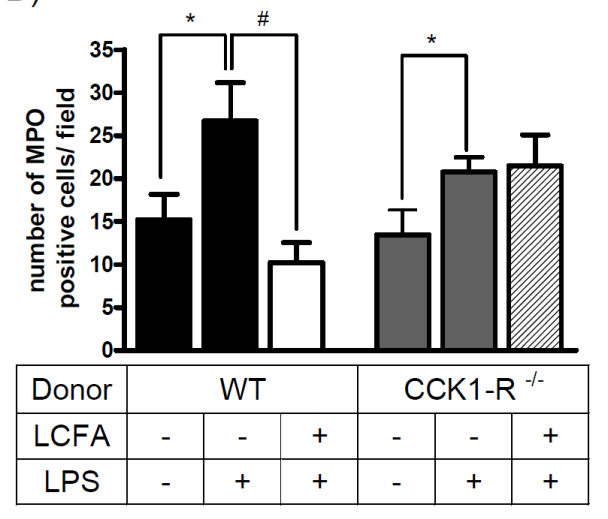

C)

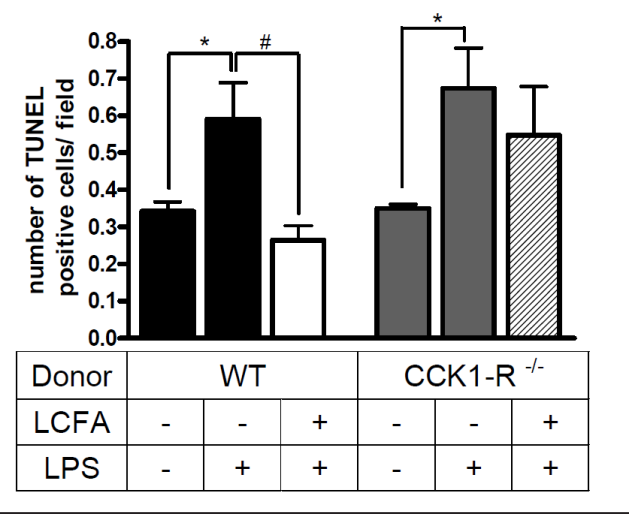

a 246-fold increase of IL-6 concentration ( $\mathrm{p}<0.05$ ), whereas in CCKR1 $\%$ animals, IL-6 only rose to 38-fold from baseline $(\mathrm{p}<0.05)$. Although WT mice exhibited a greater IL-6 excursion,

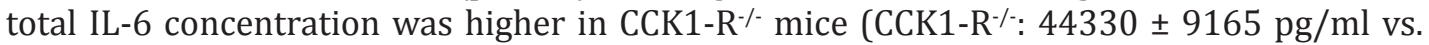
WT: $23560 \pm 4865 \mathrm{pg} / \mathrm{ml}, 3-4$ hours after LPS injection).

IL-10 concentration in the mesenteric lymph increased 30-fold in WT mice and 32fold in CCK1- $\mathrm{R}^{-1}$ mice during the first two hours after LPS challenge $(\mathrm{p}<0.05)$. Three to four hours after LPS application IL-10 concentration was increased by 54 -fold in CCK1- $\mathrm{R}^{-/}$mice reaching peak concentrations, whereas in WT mice the IL-10 concentration was already decreasing. (Fig. 2) 
Fig. 4. Representative sections of paraffin embedded lung tissue of recipient WT mice after jugular infusion of mesenteric lymph harvested during endotoxemia and enteral LCFA absorption. (A) and (B) H\&E section for measurement of alveolar wall thickness, (A) lymph donor: WT mice; (B) lymph donor: CCK1-R $\%$ mice. (C) and (D) Myeloperoxidase (MPO) staining of neutrophils, (C) lymph donor: WT mice; (D) lymph donor: CCK1-R $\mathrm{R}^{-/}$mice. (E) and (F) detection of apoptosis by TUNEL assay, (E) lymph donor: WT mice; (F) lymph donor: CCK1-R ${ }^{\%}$ mice. Original magnification, A-F $\mathrm{x}$ 400, details in $\mathrm{E}$ and $\mathrm{F} \times 1,000$.

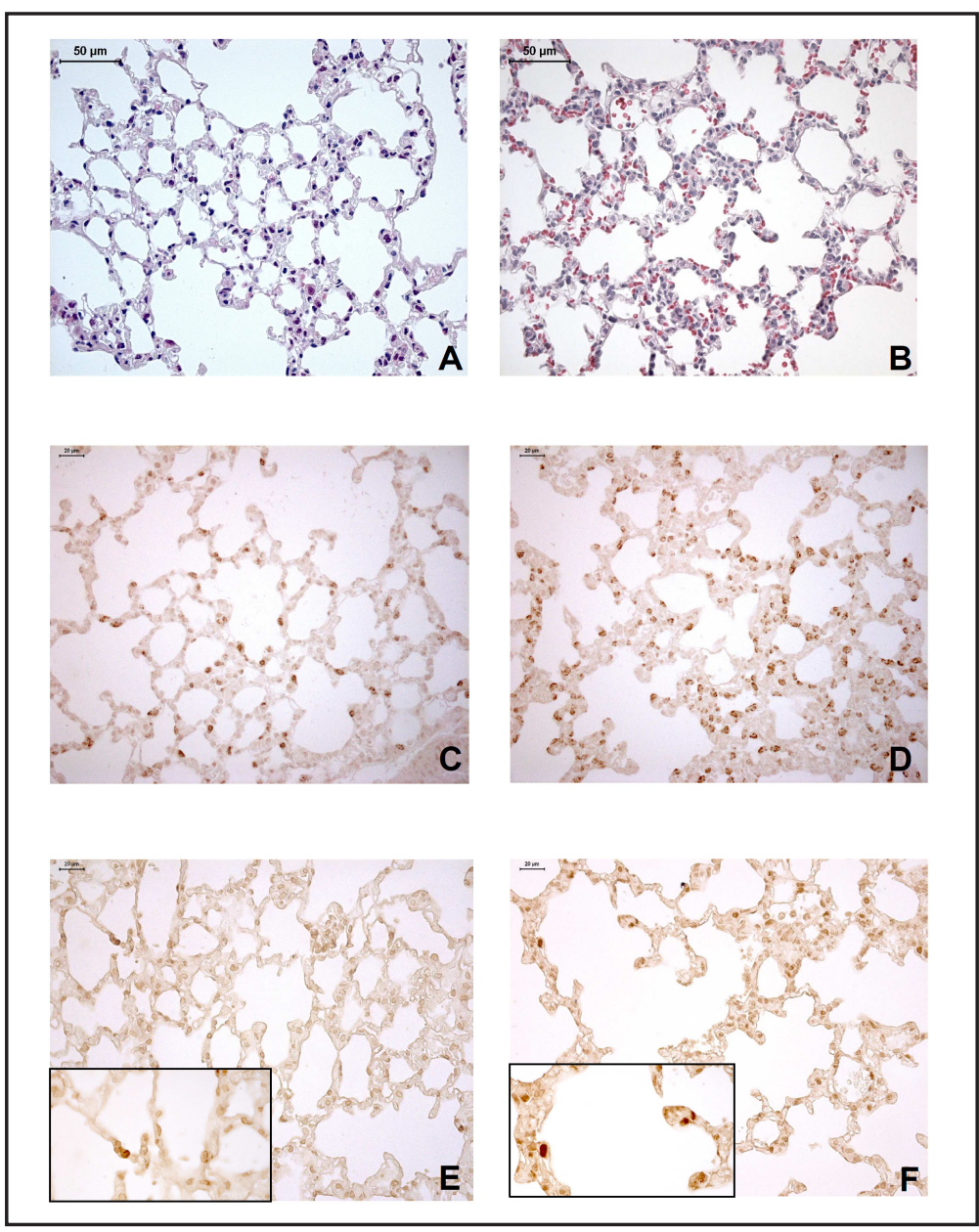

Table 1. Concentration of cytokines in pooled mesenteric lymph samples before and 1-6 hours after LPS-challenge

\begin{tabular}{lrrrrrr}
\hline Donor & \multicolumn{5}{c}{ WT } & \multicolumn{1}{c}{ CCK1-R $\%$} \\
LCFA & \multicolumn{1}{c}{-} & \multicolumn{1}{c}{+} & \multicolumn{1}{c}{+} & \multicolumn{1}{c}{-} & \multicolumn{1}{c}{-} & \multicolumn{1}{c}{+} \\
LPS & \multicolumn{1}{c}{+} & \multicolumn{1}{c}{+} & + \\
\hline TNF $\alpha[\mathrm{pg} / \mathrm{ml}]$ & 21,43 & 1134,58 & 581,93 & 10,74 & 642,87 & 641,38 \\
IL-6 [pg/ml] & 95,98 & 14548,52 & 10931,56 & 1165,61 & 22124,73 & 31343,86 \\
IL-10 [pg/ml] & 35,44 & 771,90 & 909,83 & 37,97 & 1322,26 & 1468,26 \\
\hline
\end{tabular}

Enteral long chain fatty acid absorption in WT mice reduced the amount of TNFa released into the mesenteric lymph but had no effect in CCK1R-/- mice

The baseline concentration of pro-inflammatory TNF $\alpha$ and IL-6 as well as antiinflammatory IL-10 in the mesenteric lymph was not affected by enteral LCFA absorption in both genotypes.

Absorption of LCFA reduced the TNF $\alpha$ release into mesenteric lymph by $49 \%$ in the first two hours after LPS challenge $(\mathrm{p}<0.05)$ and by $63 \%$ during the three and four hour time period in WT mice $(\mathrm{p}<0.05)$. In contrast LCFA absorption had no influence on the TNF $\alpha$ concentration in the mesenteric lymph harvested from mice lacking CCK1-R.

Enteral LCFA had no effect on lymphatic IL-6 or IL-10 concentrations after LPS challenge in either WT mice or CCK1 $\mathrm{R}^{-/}$mice (Fig. 2).

Jugular infusion of endotoxemic lymph provoked an inflammatory reaction in the lung of healthy recipient mice which was attenuated by CCK1-R activation

Jugular infusion of EL compared to jugular infusion of CL derived from WT mice (Table 1) increased the thickness of the alveolar walls in the lung of healthy WT recipient mice 
by $53 \%(\mathrm{p}<0.05)$, the number of MPO positive cells by $75 \%(\mathrm{p}<0.05)$ and the number of TUNEL-positive cells by $73 \%(\mathrm{p}<0.05)$. EL collected from CCK1R $\mathrm{R}^{-/}$mice likewise caused an augmentation in the thickness of the alveolar walls (41\%, p<0.05), MPO positive cells ( $54 \%$ $\mathrm{p}<0.05)$ and TUNEL-positive cells $(92 \% \mathrm{p}<0.05)$ in healthy recipient WT mice compared to CL collected from CCK1R ${ }^{-/-}$mice (Fig. 3, Fig. 4).

Jugular infusion of EL harvested from WT mice during enteral LCFA absorption significantly attenuated the increase of the alveolar wall thickness $(p<0.05)$, the number of MPO positive cells $(p<0.05)$ and the number of TUNEL positive cells $(p<0.05)$ compared to jugular infusion of endotoxemic lymph harvested from WT mice during enteral infusion of vehicle solution (Fig. 3, Fig. 4). In contrast, jugular infusion of EL harvested from CCK1-R ${ }^{-1-}$ mice during enteral LCFA absorption had a similar effect on the thickness of the alveolar walls, the number of MPO positive cells and the number of TUNEL positive cells as jugular infusion of EL harvested from CCK1- $\mathrm{R}^{-/}$mice with enteral infusion of vehicle solution (Fig. 3, Fig. 4).

\section{Discussion}

The GALT is considered to contain the majority of immune cells in the human body [16]. Nonbacterial, gut-derived factors are transported via mesenteric lymph into the systemic circulation [18]. A number of studies indicate the pivotal role of intestinal lymphatics in the development of ARDS and MODS [20, 27, 37]. Interruption of mesenteric lymph flow abrogates lung injury and inflammation in hemorrhagic shock $[26,27,38]$ and endotoxemia [20]. Recently we have shown that enteral absorption of LCFA diminished the harmful effects of mesenteric lymph in rats challenged with LPS $[19,39]$. The present study confirmed this finding in a mouse model and revealed insights into the involved pathway.

We used intraperitoneal LPS injection to induce endotoxemia, a model that permits high standardization and accurate dosing. To recognize lung injury we focused on parameters frequently used in animal models, resembling histological alterations of human ARDS [18, 40]: alveolar wall thickness as a measure for the distance of oxygen perfusion, quantification of MPO positive cells as measure of inflammation and the number of apoptotic cells as a marker for permanent tissue damage. All parameters of lung injury increased in recipient mice after jugular infusion of mesenteric lymph harvested during endotoxemia. Enteral LCFA absorption during lymph drainage in WT mice attenuated this harmful effect of EL. In contrast, enteral LCFA absorption in mice lacking CCK1-R did not prevent lung damage in recipient mice. Hence, CCK1-R activation is pivotal for the beneficial effect of LCFA absorption during endotoxemia.

CCK1-Rs are expressed by vagal afferents in the gut wall. Their activation results in signaling to neurons in the nucleus of the solitary tract (NTS) [34, 41-43]. NTS neurons project to the dorsal motor nucleus of the vagus (DMV) and other central areas. Parasympathetic DMV neurons activate nicotinic acetylcholine receptors expressed by postganglionic neurons in the gastrointestinal tract, thereby modulating motility, tone and secretion [44]. But nicotinic acetylcholine receptors are also detected on immune cells [31, 45]. Activation of the alpha 7 nicotinic acetylcholine receptors (n $\alpha 7 \mathrm{AChR}$ ) subtype diminishes NF- $\kappa \mathrm{B}$ translocation into the nucleus and subsequent synthesis of pro-inflammatory cytokines like TNF $\alpha$ [46].

We assumed that TNF $\alpha$, IL- 6 and IL-10 form an important fraction of gut derived nonbacterial factors, transported via mesenteric lymph and contributing to lung injury during endotoxemia. TNF $\alpha$ provokes SIRS and is regarded as a key mediator of septic shock and the related MODS [47]. IL-6 induces the acute phase response and lymphocyte differentiation $[48,49]$ but may also possess anti-inflammatory properties [49-51]. IL-10 is considered as mainly anti-inflammatory acting and its depression is associated with uncontrolled systemic inflammatory responses [52]. Intraperitoneal injected LPS strongly increased TNF $\alpha$, IL-6 and IL-10 concentration in mesenteric lymph. In WT mice enteral LCFA absorption attenuated $\mathrm{TNF} \alpha$ secretion into mesenteric lymph by almost $50 \%$, confirming previous findings in rats 
$[19,53]$. In contrast, intestinal infusion of LCFA had no effect on TNF $\alpha$ release in CCK1- $\mathrm{R}^{-/}$ mice, demonstrating the crucial role of CCK1-R activation. It has been suspected before that enteral lipid absorption modulates inflammation by cholecystokinin receptor (CCK-R) stimulation. The combined chemical blockage of both CCK-R subtypes (CCK1-R, CCK2-R) in rodent models of endotoxemia and hemorrhagic shock abrogates the lipid induced inhibition of TNF $\alpha$ release into plasma [32, 33]. Afferent fibers of the vagal nerve express CCK1-R in a three-fold higher concentration than CCK2-R [54]. Therefore we assumed that CCK1-Rs are the pivotal receptor subtype mediating the anti-inflammatory lipid effect. The abolished effect of LCFA absorption in CCK1- $\mathrm{R}^{\%}$ mice, observed here, clearly strengthens this hypothesis. To our knowledge, the present study is the first one revealing that CCK1-R stimulation is the crucial factor for attenuation of inflammatory responses by enteral LCFA absorption.

The observation that enteral LCFA absorption did not alter IL- 6 and IL-10 concentration in mesenteric lymph is in accordance with data presented by Rosas-Ballina et al.: TNF $\alpha$, but not IL- 6 and IL-10 levels in human plasma are effected by selective $\alpha 7$ agonism after LPS challenge [55]. Both cytokines are produced by a broad array of cell types [48, 49, 52], possibly explaining the absence of a significant inhibition by n $\alpha 7 \mathrm{AChR}$ stimulation.

In CCK1-R $\%$ mice LPS induced a pattern of cytokine release into mesenteric lymph which differed from the response in WT mice. TNF $\alpha$ increase in the first two hours after LPS application was lower than in WT mice. In contrast IL- 6 and IL-10 levels were higher in mesenteric lymph of CCK1-R $\mathrm{R}^{-/}$mice three to four hours after LPS application, confirming a strong innate immune response. Prior to LPS challenge IL- 6 synthesis by CCK1-R ${ }^{-/}$mice exceeded the level of WT mice. Both, IL- 6 and IL-10 have been shown to suppress TNF $\alpha$ release in experimental conditions $[50,51,56]$. Higher IL-6 levels might explain lower TNF $\alpha$ levels in CCK1- $\mathrm{R}^{-/}$mice. However, the reason for the pronounced IL-6 production in mice lacking CCK1-R remains unexplained. In summary, these data indicate immunological differences between CCK1-R $\mathrm{R}^{-/}$mice and WT mice but further attempts are needed for clarification.

Taken together, the present study demonstrates the specific role of CCK1-R stimulation in modulating the release of TNF $\alpha$ into mesenteric lymph. Probably further, currently not identified mediators in the mesenteric lymph are influenced by CCK1-R stimulation and contribute to the inhibition of endotoxemia induced lung damage. Although models of endotoxemia only partially reproduce features of human sepsis our data clearly support the concept of immunomodulation by specific nutrients and the benefit of enteral feeding.

\section{Conclusion}

Intestinal absorption of LCFA reduces the release of pro-inflammatory mediators into mesenteric lymph during endotoxemia and therefore attenuates the harmful effect of endotoxemic lymph on the lung. The anti-inflammatory effect of LCFA depends on the presence of CCK1-R. CCK1-R stimulation by a diet rich in LCFA, could provide an inexpensive and simplistic tool to prevent overwhelming inflammatory responses in critically ill patients.

\section{Conflict of Interest}

None

\section{Acknowledgements}

This work was supported by a fellowship within the Postdoc-Program of the German Academic Exchange Service (DAAD) to Friederike Eisner (D/10/49104) and NIHDDK41004 to Helen E Raybould. 


\section{References}

1 Dombrovskiy VY, Martin AA, Sunderram J, Paz HL: Rapid increase in hospitalization and mortality rates for severe sepsis in the United States: a trend analysis from 1993 to 2003. Crit Care Med 2007;35:1244-1250.

-2 Engel C, Brunkhorst FM, Bone H-G, Brunkhorst R, Gerlach H, Grond S, Gruendling M, Huhle G, Jaschinski U, John S, Mayer K, Oppert M, Olthoff D, Quintel M, Ragaller M, Rossaint R, Stuber F, Weiler N, Welte T, Bogatsch H, Hartog C, Loeffler M, Reinhart K: Epidemiology of sepsis in Germany: results from a national prospective multicenter study. Intensive Care Med 2007;33:606-618.

-3 Levy MM, Fink MP, Marshall JC, Abraham E, Angus D, Cook D, Cohen J, Opal SM, Vincent JL, Ramsay G: 2001 SCCM/ESICM/ACCP/ATS/SIS International Sepsis Definitions Conference. Crit Care Med 2003;31:12501256.

4 Bone R, Balk R, Cerra F, Dellinger R, Fein A, Knaus W, Schein RM, Sibbald WJ: Definitions for sepsis and organ failure and guidelines for the use of innovative therapies in sepsis. The ACCP/SCCM Consensus Conference Committee. American College of Chest Physicians/Society of Critical Care Medicine. Chest 1992;101:1644-1655. Bianchi ME: DAMPs, PAMPs and alarmins: all we need to know about danger. J Leukoc Biol 2007;81:1-5. Akira S, Uematsu S, Takeuchi O: Pathogen recognition and innate immunity. Cell 2006;124:783-801. Kawai T, Akira S: The role of pattern-recognition receptors in innate immunity: update on Toll-like receptors. Nat Immunol 2010;11:373-384.

8 Rittirsch D, Flierl MA, Ward PA: Harmful molecular mechanisms in sepsis. Nat Rev Immunol 2008;8:776787.

-9 Marshall JC, Cook DJ, Christou NV, Bernard GR, Sprung CL, Sibbald WJ: Multiple organ dysfunction score: a reliable descriptor of a complex clinical outcome. Crit Care Med 1995;23:1638-1652.

10 Beutler B, Rietschel ET: Innate immune sensing and its roots: the story of endotoxin. Nat Rev Immunol 2003;3:169-176.

11 Raetz CRH, Whitfield C: Lipopolysaccharide endotoxins. Annu Rev Biochem 2002;71:635-700.

-12 Shimazu R, Akashi S, Ogata H, Nagai Y, Fukudome K, Miyake K, Kimoto M: MD-2, a molecule that confers lipopolysaccharide responsiveness on Toll-like receptor 4. J Exp Med 1999;189:1777-1782.

13 Salomao R, Brunialti MKC, Rapozo MM, Baggio-Zappia GL, Galanos C, Freudenberg M: Bacterial sensing, cell signaling, and modulation of the immune response during sepsis. Shock 2012;38:227-242.

14 Okusawa S, Gelfand JA, Ikejima T, Connolly RJ, Dinarello CA: Interleukin 1 induces a shock-like state in rabbits. Synergism with tumor necrosis factor and the effect of cyclooxygenase inhibition. J Clin Invest 1988;81:1162-1172.

15 Goris RJ: MODS/SIRS: result of an overwhelming inflammatory response? World J Surg 1996;20:418-421.

16 Chandran P, Satthaporn S, Robins A, Eremin O: Inflammatory bowel disease: dysfunction of GALT and gut bacterial flora (I). Surgeon 2003;1:63-75.

17 Smith PD, Smythies LE, Shen R, Greenwell-Wild T, Gliozzi M, Wahl SM: Intestinal macrophages and response to microbial encroachment. Mucosal Immunol 2011;4:31-42.

18 Deitch EA: Gut lymph and lymphatics: a source of factors leading to organ injury and dysfunction. Ann N Y Acad Sci 2010;1207:Supl E103-111.

19 Glatzle J, Kasparek MS, Mueller MH, Binder F, Meile T, Kreis ME, Königsrainer A, Steurer W: Enteral immunonutrition during sepsis prevents pulmonary dysfunction in a rat model. J Gastrointest Surg 2007;11:719-724.

20 Watkins AC, Caputo FJ, Badami C, Barlos D, Xu DZ, Lu Q, Feketeova E, Deitch EA: Mesenteric lymph duct ligation attenuates lung injury and neutrophil activation after intraperitoneal injection of endotoxin in rats. J Trauma 2008;64:126-130.

21 Caruso JM, Feketeova E, Dayal SD, Hauser CJ, Deitch EA: Factors in intestinal lymph after shock increase neutrophil adhesion molecule expression and pulmonary leukosequestration. J Trauma 2003;55:727-733.

-22 Senthil M, Watkins A, Barlos D, Xu D-Z, Lu Q, Abungu B, Caputo F, Feinman R, Deitch EA: Intravenous injection of trauma-hemorrhagic shock mesenteric lymph causes lung injury that is dependent upon activation of the inducible nitric oxide synthase pathway. Ann Surg 2007;246:822-830.

23 Davidson MT, Deitch EA, Lu Q, Osband A, Feketeova E, Németh ZH, Haskó G, Xu DZ: A study of the biologic activity of trauma-hemorrhagic shock mesenteric lymph over time and the relative role of cytokines. Surgery 2004;136:32-41. 
24 Matthay MA, Zemans RL: The acute respiratory distress syndrome: pathogenesis and treatment. Annu Rev Pathol 2011;6:147-163.

25 Adams CA Jr, Hauser CJ, Adams JM, Fekete Z, Xu D-Z, Sambol JT, Deitch EA: Trauma-hemorrhage-induced neutrophil priming is prevented by mesenteric lymph duct ligation. Shock 2002;18:513-517.

26 Adams CA Jr, Sambol JT, Xu DZ, Lu Q, Granger DN, Deitch EA: Hemorrhagic shock induced up-regulation of P-selectin expression is mediated by factors in mesenteric lymph and blunted by mesenteric lymph duct interruption. J Trauma 2001;51:625-631; discussion 631-632.

-27 Magnotti LJ, Upperman JS, Xu DZ, Lu Q, Deitch EA: Gut-derived mesenteric lymph but not portal blood increases endothelial cell permeability and promotes lung injury after hemorrhagic shock. Ann Surg 1998;228:518-527.

28 Magnotti LJ, Xu DZ, Lu Q, Deitch EA: Gut-derived mesenteric lymph: a link between burn and lung injury. Arch Surg 1999;134:1333-1340; discussion 1340-1341.

-29 Borovikova LV, Ivanova S, Zhang M, Yang H, Botchkina GI, Watkins LR, Wang H, Abumrad N, Eaton JW, Tracey KJ: Vagus nerve stimulation attenuates the systemic inflammatory response to endotoxin. Nature 2000;405:458-462.

30 Munford RS, Tracey KJ: Is severe sepsis a neuroendocrine disease? Mol Med 2002;8:437-442.

31 Wang H, Yu M, Ochani M, Amella CA, Tanovic M, Susarla S, Li JH, Wang H, Yang H, Ulloa L, Al-Abed Y, Czura CJ, Tracey KJ: Nicotinic acetylcholine receptor alpha7 subunit is an essential regulator of inflammation. Nature 2003;421:384-388.

32 Luyer MD, Greve JWM, Hadfoune M, Jacobs JA, Dejong CH, Buurman WA: Nutritional stimulation of cholecystokinin receptors inhibits inflammation via the vagus nerve. J Exp Med 2005;202:1023-1029.

-33 Lubbers T, De Haan J-J, Hadfoune M, Zhang Y, Luyer MD, Grundy D, Buurman WA, Greve JW: Lipid-enriched enteral nutrition controls the inflammatory response in murine Gram-negative sepsis. Crit Care Med 2010;38:1996-2002.

34 Raybould HE: Mechanisms of CCK signaling from gut to brain. Curr Opin Pharmacol 2007;7:570-574.

-35 Kopin AS, Mathes WF, McBride EW, Nguyen M, Al-Haider W, Schmitz F, Bonner-Weir S, Kanarek R, Beinborn M: The cholecystokinin-A receptor mediates inhibition of food intake yet is not essential for the maintenance of body weight. J Clin Invest 1999;103:383-391.

-36 Glatzle J, Leutenegger CM, Mueller MH, Kreis ME, Raybould HE, Zittel TT: Mesenteric lymph collected during peritonitis or sepsis potently inhibits gastric motility in rats. J Gastrointest Surg 2004;8:645-652.

37 Reino DC, Pisarenko V, Palange D, Doucet D, Bonitz RP, Lu Q Colorado I, Sheth SU, Chandler B, Kannan KB, Ramanathan M, Xu da Z, Deitch EA, Feinman R: Trauma hemorrhagic shock-induced lung injury involves a gut-lymph-induced TLR4 pathway in mice. PLoS ONE 2011;6:e14829.

-38 Zallen G, Moore EE, Johnson JL, Tamura DY, Ciesla DJ, Silliman CC: Posthemorrhagic shock mesenteric lymph primes circulating neutrophils and provokes lung injury. J Surg Res 1999;83:83-88.

-39 Glatzle J, Beckert S, Kasparek MS, Mueller MH, Mayer P, Meile T, Königsrainer A, Steurer W: Olive oil is more potent than fish oil to reduce septic pulmonary dysfunctions in rats. Langenbecks Arch Surg 2007;392:323-329.

-40 Matute-Bello G, Frevert CW, Martin TR: Animal models of acute lung injury. Am J Physiol Lung Cell Mol Physiol 2008;295:L379-399.

41 Chen DY, Deutsch JA, Gonzalez MF, Gu Y: The induction and suppression of c-fos expression in the rat brain by cholecystokinin and its antagonist L364,718. Neurosci Lett 1993;149:91-94.

42 Mönnikes H, Lauer G, Arnold R: Peripheral administration of cholecystokinin activates c-fos expression in the locus coeruleus/subcoeruleus nucleus, dorsal vagal complex and paraventricular nucleus via capsaicinsensitive vagal afferents and CCK-A receptors in the rat. Brain Res 1997;770:277-288.

43 Day HE, McKnight AT, Poat JA, Hughes J: Evidence that cholecystokinin induces immediate early gene expression in the brainstem, hypothalamus and amygdala of the rat by a CCKA receptor mechanism. Neuropharmacology 1994;33:719-727.

44 Browning KN, Travagli RA: Plasticity of vagal brainstem circuits in the control of gastrointestinal function. Auton Neurosci 2011;161:6-13.

45 Gahring LC, Rogers SW: Neuronal nicotinic acetylcholine receptor expression and function on nonneuronal cells. AAPS J 2005; 7:E885-894.

46 Rosas-Ballina M, Tracey KJ: Cholinergic control of inflammation. J Intern Med 2009;265:663-679.

47 Blackwell TS, Christman JW: Sepsis and cytokines: current status. Br J Anaesth 1996;77:110-117. 
Eisner et al.: CCK1-Receptor Signaling During Endotoxemia

48 Assier E, Boissier M-C, Dayer J-M: Interleukin-6: from identification of the cytokine to development of targeted treatments. Joint Bone Spine 2010;77:532-536.

49 Papanicolaou DA, Wilder RL, Manolagas SC, Chrousos GP: The pathophysiologic roles of interleukin-6 in human disease. Ann Intern Med 1998;128:127-137.

50 Schindler R, Mancilla J, Endres S, Ghorbani R, Clark SC, Dinarello CA: Correlations and interactions in the production of interleukin-6 (IL-6), IL-1, and tumor necrosis factor (TNF) in human blood mononuclear cells: IL-6 suppresses IL-1 and TNF. Blood 1990;75:40-47.

51 Xing Z, Gauldie J, Cox G, Baumann H, Jordana M, Lei XF, Lei XF, Achong MK: IL-6 is an antiinflammatory cytokine required for controlling local or systemic acute inflammatory responses. J Clin Invest 1998;101:311-320.

52 Hedrich CM, Bream JH: Cell type-specific regulation of IL-10 expression in inflammation and disease. Immunol Res 2010;47:185-206.

53 Eisner F, Jacob P, Frick J-S, Feilitzsch M, Geisel J, Mueller MH, Küper MA, Raybould HE, Königsrainer I, Glatzle J: Immunonutrition with long-chain fatty acids prevents activation of macrophages in the gut wall. J Gastrointest Surg 2011;15:853-859.

54 Moriarty P, Dimaline R, Thompson DG, Dockray GJ: Characterization of cholecystokininA and cholecystokininB receptors expressed by vagal afferent neurons. Neuroscience 1997;79:905-913.

55 Rosas-Ballina M, Goldstein RS, Gallowitsch-Puerta M, Yang L, Valdés-Ferrer SI, Patel NB, Chavan S, AlAbed Y, Yang H, Tracey KJ: The selective alpha7 agonist GTS-21 attenuates cytokine production in human whole blood and human monocytes activated by ligands for TLR2, TLR3, TLR4, TLR9, and RAGE. Mol Med 2009;15:195-202.

56 Gérard C, Bruyns C, Marchant A, Abramowicz D, Vandenabeele P, Delvaux A, Fiers W, Goldman M, Velu T: Interleukin 10 reduces the release of tumor necrosis factor and prevents lethality in experimental endotoxemia. J Exp Med 1993;177:547-550. 